\title{
Confirmatory Factor Analysis of the Career Feedback Inventory in an Iranian High School Students Sample
}

Iranian Evolutionary and Educational Psychology Journal March 2020: 46-56 (C) University of Hormozgan Publication 2020 DOI: http://ieepj.hormozgan.ac.ir

\author{
Ahmad Sadeghi ${ }^{1 *}$, Parisa Doostani ${ }^{2}$, Shi Hu ${ }^{3}$
}

\begin{abstract}
The purpose of the present study was to examine the structural and construct validity of the FCG inventory as applied in Iran. Feedback on Career Goals (FCG) Inventory was devised and validated by Hu, Creed, and Hood (2017) and was later used to measure career feedback among Chinese and Australian university students. The statistical population of this study consisted of all high school students in Isfahan in the academic year of 2018-2019, and 324 students (166 females and 158 males) were selected through cluster sampling as the sample size. Then, the students were administered a translated version of the FCG inventory, and their responses were examined with respect to the structure of the inventory. Results of confirmatory factor analyses demonstrated that three factors of feedback on progress, goal suitability, and improvements needed loaded on one higher-order factor of career feedback, similar to the structure of the FCG inventory applied in Chinese and Australian students. The results also provided support for construct validity of the scale by linking career feedback with career goal-performance discrepancies and career-related stress. Our findings suggest that the Iranian version of the FCG inventory has acceptable psychometric properties and is a valid instrument for the assessment of career feedback.
\end{abstract}

Keywords: career goal feedback, confirmatory factor analyses, high school students

\section{Introduction}

Theoretically and practically personal goals are important; individuals use goals to regulate their behavior and effort (Button, Mathieu, \& Aikin, 1996; Donovan \& Williams, 2003). In order to regulate their behavior, individuals need feedback so that they can assess their previous performance in comparison with their goals. Feedback is one of the most important factors, affecting on career decision making and achievement, but this effect can be either positive or negative (Hattie \& Timperley, 2007). That is, receiving feedback is not always a positive experience, nor does it always lead to positive outcomes (Ilgen, Fisher, \& Taylor, 1979; Kluger \& DeNisi, 1996, 1998).

Feedback is a component of learning that plays a crucial role in the success of individuals. Feedback will put people in a position to compare their performance with their ideal goals (Schartel, 2012). In other words, Feedback means "returning" the effects of actions by the environment or others to the subject of action. In

1. Department of counseling, Faculty of Education and Psychology, University of Isfahan, Isfahan, Iran

*Corresponding author email: a.sadeghi@edu.ui.ac.ir

2. Department of counseling, Faculty of Education and Psychology, University of Isfahan, Isfahan, Iran

3. School of Education Science, Nanjing Normal University, Nanjing 210000, Jiangsu Province, China 
feedback, the evidence is returned to people without being interpreted or evaluated so that they can adjust their behavior to their goals (Khoshkholgh, 2011).

Magill and Anderson (2007) believed that, feedback is the information that a person receives when he or she performs skills during or after the execution. Presenting rapidly, consistent, and accurate feedback increases people's performance.

Feedback is conceptualized as information provided by an agent (e.g., teacher, peer, parent, self, and experience) based on aspects of one's performance or understanding (Hattie \& Timperley, 2007). For example, a teacher or parent can provide corrective information, a peer can provide a substitutive strategy, a parent can provide encouragement, and a learner can look up the answer to evaluate the authenticity of a response. Feedback, thus, is a "consequence" of performance. Butler and Winne (1995) Believed that "feedback is information with which a student can confirm, add to, overwrite, tune, or restructure information in memory, whether that information is domain knowledge, meta-cognitive knowledge, beliefs about self and tasks, or cognitive tactics and strategies".

Ramsden (1988) Believed that constructive feedback plays an important role in the individual's career. That is one of the influencing factors on individual's motivation among the learners. As a result, effective feedback for students is an important factor in their future career. Effective feedback generates useful information about how it works and about its results. It also enables them to compare actual results with the ideal results driven by this motive that may cause changing them. Iranian high school student should decision making about their major when they trying to prepare for university entrance exam, feedback can help students to making decision effectively. In particular, teachers can utilize feedback to pledge effective instructions (Hattie \& Timperley, 2007). In addition, there are many possible ways for students to use feedback to lessen the gap between current and desired understandings. For example, students can increase their effort, particularly when the effort leads to tackling more challenging tasks or appreciating higher quality experiences rather than just doing "more." People are more likely to increase effort when the intended goal "is clear, when high commitment is secured for it, and when belief in eventual success is high" (Kluger \& DeNisi, 1996, p. 260).

Researchers such as Koh (2008) and Chowdhury and Kalu (2004) consider the impact of constructive feedback more than the learning and teaching process, as long as feedback is important to guide learners and increases the motivation, confidence and self-esteem in them. In other by way of explanation, the incorrect and poor usage of feedback causes people to fail, and create disillusionment, anger and aggression in them.

In Iran, the results of Jabariangroo, Khosravi, and Mohammadifar (2016)'s research showed that there was a significant difference in the self-regulation and academic achievement of students in experimental group compared to the control group after getting feedback. Hattie \& Timperley (2007) by studying the evidence of the effect of feedback on learning and success, concluded that the type and method in presenting the feedback has different effects.

Being Successful in entrance exam and entering the university are due to various factors (Doostani \& Sadeghi, 2018). One of the factors that influences academic achievement and, of course, university entrance exam is career goal feedback. Career goal feedback is the information that received according to the suitability of the career goal. Different researchers believed that career feedback plays an important role in evaluating individual's career goals (Creed, Wamelink, \& Hu, 2015), determining the career goal (Dobrow \& Tosti-Kharas, 2012), strategies for career exploration (Anderson \& Mounts, 2012) and the health of the career (Creed et al., 2015). 
For a long time, evaluation students' performance has been gradual and inevitable. On the other hand, assessing the students' academic performance provides feedback to them, in such a way that these feedbacks affect the future performance of the individual (Waddell, 2004).

Several assessment instruments have been developed to measure the construct of career feedback, including the eight-item feedback on career progress from significant others scale(Creed \& Hood, 2015), the five-item feedback subscale of the job characteristics inventory (assessing performance feedback); (Sims, Szilagyi, \& Keller, 1976), and the 32-item feedback scale (Herold \& Greller, 1977). However, these scales do not assess the three domains of goal suitability, goal progress, and future actions, as recommended by Hattie and Timperley (2007). The master students' perceptions of supervisor feedback scale (de Kleijn, Mainhard, Meijer, Pilot, \& Brekelmans, 2012) was developed based on Hattie and Timperley's (2007) feedback framework, but was limited to use with masters' students. To assess all important dimensions of the construct, Hu et al. (2017) have developed the FCG inventory. This scale incorporates two sources for feedback of external feedback and internal feedback. External sources include feedback from peers, parents, supervisors, while internal feedback involves self-judgment and evaluation, and reflects one's own feelings and intuition about the current situation against the ideal state. These two sources of feedback can be consistent with, or conflicting to each other (Butler \& Winne, 1995). Also, for each feedback source (i.e., external and internal), the scale taps three important domains of feedback: as career goal suitability, goal progress, and improvements or adjustments needed.

Hu et al. (2017) provided support for structural validity of the scale in Chinese and Australian young people. Purpose of the Current Study: The purpose of the present study was to examine the structural and construct validity of the FCG inventory as applied in Iran. As mentioned before, there is no appropriate measure of career feedback for Iranian adolescents. It is important for Iranian high school students to assess their career goal feedback, as they have to determine the career goal relevant to their future job before being admitted to the university or learning the required skills in order to entering a job. However, High school students in Iran are preparing for university entrance exam. This exam is of great significance for its inclusiveness in a public university and the desired field of study affects their career prospects.

One of the factors affecting academic motivation and self-efficacy is career goal feedback. Measuring and determining the level of internal and external negative feedback that students receive can be effective in designing appropriate interventions to enhance their motivation and academic self-efficacy. One of the most challenging academic years for any Iranian students is 4th year of high school and participating university's entrance exam. All the students who compete in the entrance exam are hope to gain a good rank in order to be accepted in an ideal major and high rank university.

As it mentioned before, the appropriateness of assessing career feedback in high school students in Iran has several roles in learning process to achieve success and goals. In fourth-grade students, providing the right feedback has a major function in information and motivation. In such a way that learners correct their mistakes by receiving appropriate feedback, and stabilize their lessons. On the subject of motivational role, providing the right feedback, increases energy and encourages them to move forward towards their career goals, in fact, it encourages the student to move with effort and perseverance towards their intended goal (Schmidt \& Lee, 1998). 
In addition, providing appropriate feedback from people around them helps fourth-grade students to identify the main factors of their success and attribute the success to their ability and the fail to not trying. If feedback has been presented properly, helps to create creativity and improve students' skills (McLaughlin, Rogers, \& Fisk, 2006).

The importance of feedback for fourth-year students is to deepen the learning procedure and it clarifies what actions are required to do in order to reach the career goals. Because of these, it seems to be necessary to provide a valid measure for Iranian high school students.

\section{Material and Method}

Translation: The English-version of the career goal feedback and the validity scales (Career goal-performance discrepancy and Korean College Stress Inventory) were translated into Farsi using standard translation/back-translation methodology (Jones, Lee, Phillips, Zhang, \& Jaceldo, 2001). The first author translated the items into Farsi, and confirmed by three bilingual experts in career counseling. After the Farsi form was back-translated into English (by the author), A native English speaker from U.S. compared the back-translated versions with the originals and made adjustments where required. The final questionnaires were then piloted with four high school students (age range $=17-18$ years) to assess language level and readability.

Participants: Isfahan, is Iran's third largest city following Tehran and Mashhad, with a population of 1.5 million people. All high school students in the city of Isfahan, who were studying in the academic year of 2018-2019, formed the statistical population of this study. Participant were selected through cluster sampling method (separately in the fields of mathematics, natural sciences and humanities). Finally, according to Wolf, Harrington, Clark, and Miller (2013) suggestion on minimum sample size in structural equation models, 324 questionnaires were collected for data analysis. They suggested sample sizes of 300 for models with 7 structures or less and a low contribution to factor models.

The students had a mean age of 17.5 years ( $\mathrm{SD}=1$ years), and included 166 females $(51.23 \%)$ and 158 males $(48.76 \%)$.

Measures: Career Goal Feedback Scale. To measure career goal feedback, the 24-item FCG Inventory (Hu et al., 2017) was used, which assesses students' perceptions of the level of negative career feedback they are receiving. This scale used 6-point Likert-type response $(1=$ strongly disagree, $2=$ disagree, $3=$ somewhat disagree, 4 = somewhat agree, 5 =agree, 6 = strongly agree(Hu et al., 2017). Career goal feedback contains three subscales including goal suitability (8items; information on whether the goals fit the person's temperament, abilities, and values), current career progress ( 8 items; information on whether the goals are met by being engaged, hard-working, and achievement focused), and improvement needed ( 8 items; information on how goals can be advanced). Hu et al. (2017) reported sound internal reliability for the three subscales (Cronbach's $\alpha=.77, .83$, and .82 , respectively) and supported validity by finding that negative career feedback was related to career related stress. Alpha coefficients with the current sample were $.83,86$, and .86 , respectively.

Career Goal-performance Discrepancy. The 12-item career goal discrepancy scale with 6-point Likert-type response from number 1 for strongly disagree to number 6 for strongly agree (Creed \& Hood, 2015) was used to assess student perceptions of the level of discrepancy between their career goals and their current state of progress. Creed and Hood (2015) reported a Cronbach's $\alpha$ of .93 with Australian university students. Validity estimates indicated a one-factor structure and that perceived career goal-progress discrepancy was related to 
lower goal commitment and greater career-related stress as expected. By using CFA, we confirmed that the translated scale had a one-factor structure. In the current study, alpha coefficient was .91.

Korean College Stress Inventory. The five-item Career Ambiguity subscale assesses stress associated with students' lack of confidence and certainty about their future career. Responses were given on a 5-point Likerttype scale $(1=$ strongly disagree to $5=$ strongly agree; higher scores indicate greater stress $)$. The subscale had good reliability ( $\alpha=.89$ and .92 in two studies) and validity with Korean students (e.g., correlated with lack of self-identity); (Choi et al., 2011; Kim et al., 2014). In the current study, we confirmed that the translated scale had a one-factor structure by using CFA. Alpha coefficient with the current sample was .90 .

Procedure: Ethical approval was granted by the first authors' university ethics committee, and permission to recruit participants was obtained from the Ministry of Education.Participants were recruited using cluster sampling, whereby the researchers randomly chose 13 high schools (seven males, six female) in Isfahan. Participants' classroom teachers administered all questionnaires. Students were informed about the research purpose and asked to answer all of the questionnaires. Students were assured that all their information would remain confidential and informed that they could learn more about their individual results from our telegram channel one month after data collection.

\section{Results}

Reliability :The reliability estimates are shown and compared with the results reported by $\mathrm{Hu}$ et al (2017) in Table 1. The internal consistency reliability for the full scale was .88, and was .86 (feedback on progress), .83 (on goal suitability), and .86 (on improvements needed) for the three subscales. Cronbach's Alpha values between .60 and 1.00 indicate that a measurement instrument is good and suitable for use in a study (Hu et al., 2017). In addition, all items showed high Cronbach's Alpha. Cronbach Alpha of each item indicates instrument has reliability (reference).

Validity test: We first conducted CFA analyses with maximum likelihood estimation (AMOS V20) to validate the factor structure of the 24-item FCG inventory. Model fit was indicated by the $\chi 2$ / df ratio ( $<3: 1$ desired), the comparative fit index (CFI) and Tucker-Lewis index (TLI; >.90), the root mean square error approximation (RMSEA) and standardized root mean square residual (SRMR; <.08); (Hair, Black, Babin, \& Anderson, 2010). Second, we assessed construct validity of the feedback scale by linking it with other career relevant variable (career goal- performance discrepancy and career-related stress).

To test if the structure of FCG inventory was consistent with the Chinese and Australian population, we examined whether each item loaded on their respective subscales. As shown in figure 1, the six first-order factors of internal and external feedback on progress, goal suitability, and improvements needed loaded on three second-order factors (i.e., feedback on progress, goal suitability, and improvements needed), which, in turn, loaded on one higher-order factor of career goal feedback.

For the most part, items loaded onto their respective factors, except for item 21 from internal goal suitability subscale. The measurement model with item 21 included showed acceptable fit to the data: CFI $=.91$, TLI $=$ $.90, \mathrm{RMSEA}=.063, \mathrm{SRMR}=.071$. After omitting item 21, the measurement model fit indices improved: CFI $=.95, \mathrm{TLI}=.94, \mathrm{RMSEA}=.045, \mathrm{SRMR}=.043($ see Table 2$)$. 
Table 1. Principal axis factor analysis in this study and Hu et al.'s study (2016) and Cronbach's Alpha ( $\alpha$ ) of each item

\begin{tabular}{|c|c|c|c|}
\hline Items & $\begin{array}{l}\mathrm{P} \text { In present } \\
\text { study }\end{array}$ & $\begin{array}{l}\text { P In Hu et al.'s study } \\
(2016)\end{array}$ & $(\alpha)$ \\
\hline \multicolumn{4}{|l|}{ Internal: how to improve } \\
\hline 1. I have not worked out my own strategies to get the career I want & .70 & .83 & .91 \\
\hline 2. I feel uncertain about what I have to do to reach my career goals & .76 & .72 & .91 \\
\hline $\begin{array}{l}\text { 3. Even by looking at what others are doing, I cannot see what I need to do to get the } \\
\text { career I want }\end{array}$ & .72 & .67 & .91 \\
\hline 4.I do not have many ideas about how to reach my career goals & .70 & .62 & .91 \\
\hline \multicolumn{4}{|l|}{ External: how to improve } \\
\hline 5. I do not get helpful advice from others about how I can reach my career goals & .86 & -.92 & .91 \\
\hline 6. I do not get helpful information from people about how to get into the career I want & .88 & -.83 & .91 \\
\hline $\begin{array}{l}\text { 7. I do not get good guidance from the people around me about progressing my career } \\
\text { goals }\end{array}$ & .79 & -.71 & .91 \\
\hline 8. I find it hard to get constructive career advice from others & .64 & -.92 & .91 \\
\hline \multicolumn{4}{|l|}{ External: on progress } \\
\hline 9. People tell me that I am not working hard enough to get into my chosen career & .73 & -.53 & .91 \\
\hline $\begin{array}{l}\text { 10. People around me tell me that I am not motivated enough to achieve my chosen } \\
\text { career }\end{array}$ & .76 & .71 & .91 \\
\hline $\begin{array}{l}\text { 11. People tell me that what I have achieved so far is not good enough to get into the } \\
\text { career I want }\end{array}$ & .80 & .67 & .91 \\
\hline 12. I am told that I am not making good progress toward my career goals & .74 & .61 & .91 \\
\hline \multicolumn{4}{|l|}{ External: goal suitability } \\
\hline 13. I am told that my preferred career choice will not let me display my real talents & .60 & .76 & .91 \\
\hline $\begin{array}{l}\text { 14. People I trust think that my preferred career direction is not consistent with my } \\
\text { values }\end{array}$ & .72 & .68 & .91 \\
\hline 15. People tell me that I have chosen a career direction that does not really suit me & .67 & .62 & .91 \\
\hline $\begin{array}{l}\text { 16. People who know me well think that my chosen career will not bring me what I } \\
\text { really want in life }\end{array}$ & .78 & .61 & .91 \\
\hline \multicolumn{4}{|l|}{ Internal: on progress } \\
\hline 17. I know that the career progress I have made is less than that of others of my age & .56 & .66 & .91 \\
\hline 18. My experience tells me that I am not progressing my career goals as well as I should & .73 & .59 & .91 \\
\hline $\begin{array}{l}\text { 19. When I reflect on it, I don't think I have made as much progress toward my chosen } \\
\text { career as I wanted }\end{array}$ & .80 & .59 & .91 \\
\hline 20. Compared with others of my age, I think I am less on track for the career that I want & .73 & .57 & .91 \\
\hline \multicolumn{4}{|l|}{ Internal: goal suitability } \\
\hline 21. The career direction I have chosen feels right to me & .26 & .89 & .91 \\
\hline 22. I do not think that my chosen career would be good for me & -.45 & .59 & .91 \\
\hline 23. My career goals do not excite me & -.75 & .56 & .91 \\
\hline 24. My career plans make a lot of sense to me & .36 & .44 & .91 \\
\hline
\end{tabular}

So would item 21 be removed. The item descriptive statistics and loadings in the confirmatory factor model were presented in Table 3. The results showed that the third-order of career goal feedback was reliable since the standardized loadings for the three second-order factors were above .50 (current career progress $=.96$, goal suitability $=.93$, improvement needed $=.84)$. Also, all the item loadings were above .50 (except for item 21$)$. The average variance extracted (AVE) was increasing as well since the variance explained in the construct was 
associated with the standardized loadings.

We examined the construct validity of the FCG inventory by examining the relationships between career goal feedback and career goal-performance discrepancy and career-related stress. As shown in Table 3, the full feedback scale and the three second-order subscales correlated with greater career goal- performance discrepancy and stress, indicating that high school students who perceived more negative feedback have more stress.

Table 2. Comparison of Third-order confirmatory factor analyses between present study: Sample (n = 324) and Hu et al.'s study (2016): sample $(\mathrm{n}=524)$

\begin{tabular}{|c|c|c|}
\hline \multicolumn{2}{|c|}{ Before omitted the item 21} & After omitted the item 21 \\
\hline$\chi^{2}$ & 516.43 & 354.23 \\
\hline df & 239 & 202 \\
\hline$\chi^{2 / d f}$ & 2.16 & 1.75 \\
\hline$\overline{\mathrm{BIC}}$ & 869.056 & 782.01 \\
\hline TLI & .90 & .94 \\
\hline CFI & .91 & .95 \\
\hline RMSEA & .06 & .04 \\
\hline $90 \% \mathrm{CI}$ & {$[1.78,2.19]$} & {$[.04, .05]$} \\
\hline SRMR & .07 & .05 \\
\hline
\end{tabular}

Table 3. Mean, standard deviation, Cronbach's Alpha $(\alpha)$ and Pearson's Product-moment Correlations between Three Subscales of Career Goal Feedback Scale and Total Career Goal-Performance Discrepancy Scale and Total Korean College Stress Inventory; $\mathrm{N}=324$

\begin{tabular}{|l|l|l|l|l|l|l|l|l|}
\hline Variable & \multicolumn{1}{|c|}{1} & \multicolumn{1}{|c|}{2} & \multicolumn{1}{c|}{3} & \multicolumn{1}{c|}{4} & \multicolumn{1}{c|}{5} & \multicolumn{1}{c|}{ SD } & $\alpha$ \\
\hline 1. Current career progress & 1 & & & & & 21.60 & 7.86 & .86 \\
\hline 2. Goal suitability & $.564^{* *}$ & 1 & & & & 24.03 & 8.27 & .83 \\
\hline 3. Improvement needed & $.695^{* *}$ & $.577^{* *}$ & 1 & & & 19.11 & 6.54 & .86 \\
\hline 4. T feedback & $.875^{* *}$ & $.845^{* *}$ & $.860^{* *}$ & 1 & & 64.75 & 19.50 & .91 \\
\hline 5. T discrepancy & $.649^{* *}$ & $.628^{* *}$ & $.621^{* *}$ & $.736^{* *}$ & 1 & 35.88 & 12.81 & .91 \\
\hline 6.T stress & $.622^{* *}$ & $.671^{* *}$ & $.631^{* *}$ & $.747^{* *}$ & $.725^{* *}$ & 56.99 & 15.26 & .90 \\
\hline
\end{tabular}

**. Correlation is significant at the .01 level (2-tailed). 


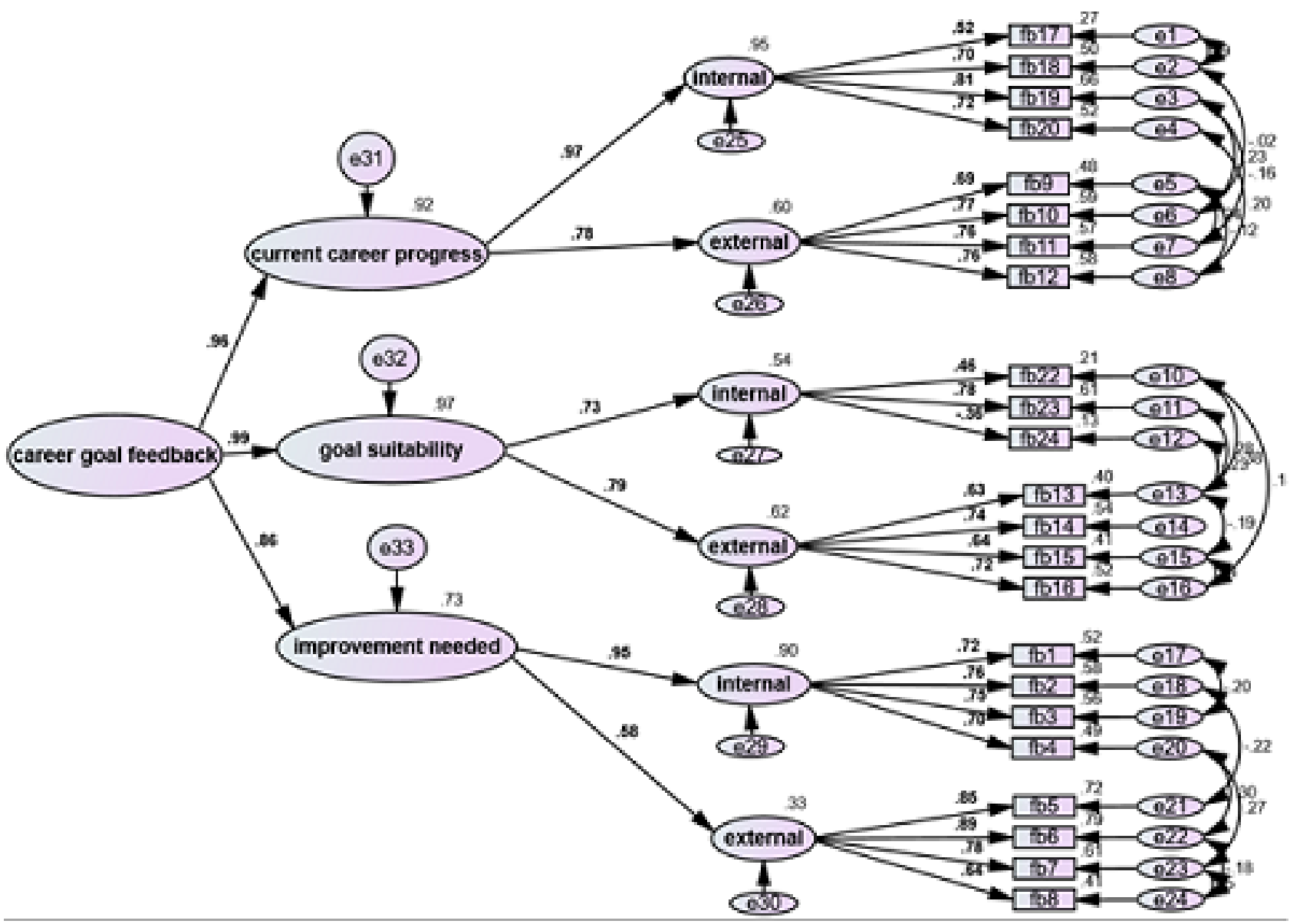

Figure 1. Third-order CFA

\section{Discussion}

The present study provided support for using the 24-item FCG inventory with Iranian high school students. Satisfactory to good internal reliability coefficients were obtained for all subscales (current career progress, goal suitability and improvement needed). These coefficients were comparable to those found by $\mathrm{Hu}$ et al., (2017) using Chinese and Australian students.

Construct validity for the test was supported using factor analysis, with individual items loading largely where expected. All internal and external subscales loaded onto their respective factors, except item 21 from internal: goal suitability. In Iran, high school students cannot decide on their field of study at the university. Because it depends on the outcome of the university entrance exam. Therefore, their career are ambiguous. Item 21 is about assurance of career. Accordingly, this question was not understood by Iranian students.

Construct validity was supported by examining the relationships between career goal feedback and career goal-performance discrepancies and career-related stress. Negative career goal feedback was associated with greater perceived discrepancies. It means that when students receive higher levels of negative feedback indicating a lack of progress and strategies for improvements and goal-person misfit, they are more likely to perceive discrepancies between their actual state and their desired state. We also found that negative career goal feedback was related to greater career stress, which means when students receive more negative feedback, they may experience higher levels of anxiety and frustration about their future career. 
Practical Implications: The focus of this study was on career progress and highlighted the effect of career feedback on students' academic outcomes. The 24-item FCG inventory appears to be an appropriate instrument to assess negative career feedback in Iranian high school students.

The assessment of career feedback is important for Iranian high school students. In this period of study, high school students need to be informed of what career path they should choose for their future. This information can greatly help to provide early career guidance in order to help students clarify their career goals, and evaluate the attainability and suitability of the goals. Given the dearth of appropriate and psychometrically sound, brief measures of career goal feedback in the career development literature in general, and the lack of scales in the Farsi language, it is important to continue to use this inventory to examine the effect of career feedback on high school student's career goal setting and pursuit.

This measure can be used in career counseling and educational programs with adolescents. For example, it could be used as a screening tool to identify which students are experiencing greater negative career goal feedback and feedback-induced stress. Also, career counselors can use the scale to help students identify the sources of the feedback (i.e., external environment or internal sources), and help them monitor their own thoughts and reflections on career goal pursuit.

Career counselors are also encouraged to use the inventory to help Iranian high school students identify the specific type of career feedback they perceive, and to help them adjust their behaviors or goals accordingly. In addition, counselors can help these students manage the potential negative affective outcomes (e.g., career stress) of perceiving negative career feedback.

Limitations and Future Directions: The current findings should be interpreted in light of the study's limitations. First, our sample was restricted to students from one city. Testing in Iran is required to assess a more heterogeneous sample of Iranian children (i.e., from different cities, and from rural areas).

Second, the study focused on the educational context of the high school students. Thus, it is not clear to whether similar results would be found in other samples (e.g., university) and other age groups in Iran. Thus, future research is needed to investigate the utility of the scale in other populations.

Third, future research is needed to provide more evidence for the validity of the Iranian version of the FCG inventory. In the current cross-sectional study, we were not able to assess predictive validity, and this needs to be assessed in the future In the future. For example, longitudinal studies could assess if higher scores on the Feedback Career Goals Inventory predicted subsequent changes in career self-efficacy.

\section{Declaration of Conflicting Interests}

The author(s) declared no potential conflicts of interest with respect to the research, authorship, and/or publication of this article.

Funding: The author(s) received no financial support for the research, authorship, and/or publication of this article.

\section{References}

Anderson, K. L., \& Mounts, N. S. (2012). Searching for the self: An identity control theory approach to triggers of occupational exploration. The Journal of genetic psychology, 173(1), 90-111.

Butler, D. L., \& Winne, P. H. (1995). Feedback and self-regulated learning: A theoretical synthesis. Review of 
educational research, 65(3), 245-281.

Button, S. B., Mathieu, J. E., \& Aikin, K. J. (1996). An Examination of the Relative Impact of Assigned Goals and Self-Efficacy on Personal Goals and Performance Over Time. Journal of Applied Social Psychology, 26(12), 1084-1103.

Choi, B. Y., Park, H., Nam, S. K., Lee, J., Cho, D., \& Lee, S. M. (2011). The development and initial psychometric evaluation of the Korean Career Stress Inventory for college students. The Career Development Quarterly, 59(6), 559-572.

Chowdhury, R. R., \& Kalu, G. (2004). Learning to give feedback in medical education. The Obstetrician \& Gynaecologist, 6(4), 243-247.

Creed, P. A., \& Hood, M. (2015). The development and initial validation of a scale to assess career goal discrepancies. Journal of Career Assessment, 23(2), 308-317.

Creed, P. A., Wamelink, T., \& Hu, S. (2015). Antecedents and consequences to perceived career goal-progress discrepancies. Journal of Vocational Behavior, 87, 43-53.

de Kleijn, R. A., Mainhard, M. T., Meijer, P. C., Pilot, A., \& Brekelmans, M. (2012). Master's thesis supervision: Relations between perceptions of the supervisor-student relationship, final grade, perceived supervisor contribution to learning and student satisfaction. Studies in Higher Education, 37(8), 925-939.

Dobrow, S. R., \& Tosti-Kharas, J. (2012). Listen to your heart? Calling and receptivity to career advice. Journal of Career Assessment, 20(3), 264-280.

Donovan, J. J., \& Williams, K. J. (2003). Missing the mark: effects of time and causal attributions on goal revision in response to goal-performance discrepancies. Journal of Applied Psychology, 88(3), 379.

Doostani, P., \& Sadeghi, A. (2018). The Effect of Career Goal Feedback on Academic Buoyancy: The Mediating role of Career Goal Discrepancy and Career-Related Stress. journal of Career \& Organization Counseling, 9(33), 49-67.

Hair, J., Black, W., Babin, B., \& Anderson, R. (2010). Multirative data analysis: A global perspective: New Jersey: Pearson Prentice Hall.

Hattie, J., \& Timperley, H. (2007). The power of feedback. Review of educational research, 77(1), 81-112.

Herold, D. M., \& Greller, M. M. (1977). Feedback the definition of a construct. Academy of Management Journal, 20(1), 142-147.

Hu, S., Creed, P. A., \& Hood, M. (2017). Development and initial validation of a measure to assess career goal feedback. Journal of Psychoeducational Assessment, 35(7), 657-669.

Ilgen, D. R., Fisher, C. D., \& Taylor, M. S. (1979). Consequences of individual feedback on behavior in organizations. Journal of Applied Psychology, 64(4), 349.

Jabariangroo, M., Khosravi, M., \& Mohammadifar, M. A. (2016). Effect of the Teacher's Oral and Written Feedback on Self-Regulated Learning and Academic Achievement in Math. Research in Curriculum Development, 22(49), 151-138.

Jones, P. S., Lee, J. W., Phillips, L. R., Zhang, X. E., \& Jaceldo, K. B. (2001). An adaptation of Brislin's translation model for cross-cultural research. Nursing research, 50(5), 300-304.

Khoshkholgh, E. (2011). Principle and Practical Guide to Preparing and Providing regarding university studentds' academic performance. World Applied Science, 26(10).

Kim, B., Jung, S. H., Jang, S. H., Lee, B., Rhee, E., Cho, S. H., \& Lee, S. M. (2014). Construction and initial 
validation of the Planned Happenstance Career Inventory. The Career Development Quarterly, 62(3), 239253.

Kluger, A. N., \& DeNisi, A. (1996). The effects of feedback interventions on performance: A historical review, a meta-analysis, and a preliminary feedback intervention theory. Psychological bulletin, 119(2), 254.

Kluger, A. N., \& DeNisi, A. (1998). Feedback interventions: Toward the understanding of a double-edged sword. Current directions in psychological science, 7(3), 67-72.

Koh, L. C. (2008). Refocusing formative feedback to enhance learning in pre-registration nurse education. Nurse Education in Practice, 8(4), 223-230.

Magill, R. A., \& Anderson, D. I. (2007). Motor learning and control: Concepts and applications (Vol. 11): McGraw-Hill New York.

McLaughlin, A. C., Rogers, W. A., \& Fisk, A. D. (2006). Importance and interaction of feedback variables: A model for effective, dynamic feedback: Georgia Institute of Technology.

Ramsden, P. (1988). Studying learning: Improving teaching. Improving learning: New perspectives, 13-31.

Schartel, S. A. (2012). Giving feedback-An integral part of education. Best practice \& research Clinical anaesthesiology, 26(1), 77-87.

Schmidt, R., \& Lee, T. (1998). Motor Control \& Learning-5th ED. Champaign: Human Kinetics.

Sims, H. P., Szilagyi, A. D., \& Keller, R. T. (1976). The measurement of job characteristics. Academy of Management journal, 19(2), 195-212.

Waddell, C. A. (2004). The effects of negotiated written feedback within formative assessment on fourth grade students' motivation and goal orientations.

Wolf, E. J., Harrington, K. M., Clark, S. L., \& Miller, M. W. (2013). Sample Size Requirements for Structural Equation Models: An Evaluation of Power, Bias, and Solution Propriety. Educ Psychol Meas, 76(6), 913934. doi: 10.1177/0013164413495237 